\title{
'What's coming up in the exam?' A survey of teachers and the delivery of a gender-balanced curriculum
}

\section{Deirdre Raftery , Judith Harford, Maryann Valiulis \& Jennifer Redmond}

To cite this article: Deirdre Raftery , Judith Harford , Maryann Valiulis \& Jennifer Redmond (2007) 'What's coming up in the exam?' A survey of teachers and the delivery of a gender-balanced curriculum, Irish Educational Studies, 26:1, 107-117, DOI: 10.1080/03323310601125336

To link to this article: https://doi.org/10.1080/03323310601125336

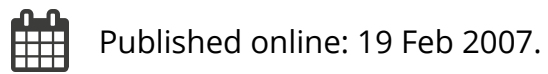

Submit your article to this journal 준

山 Article views: 180 


\title{
'What's coming up in the exam?' A survey of teachers and the delivery of a gender-balanced curriculum
}

\author{
Deirdre Raftery ${ }^{\mathrm{a}}$, Judith Harford ${ }^{\mathrm{a}}$, Maryann Valiulis ${ }^{\mathrm{b}}$ and \\ Jennifer Redmond ${ }^{\text {b }}$ \\ ${ }^{\mathrm{a}}$ University College Dublin, Ireland; ${ }^{\mathrm{b}}$ Trinity College Dublin, Ireland
}

\begin{abstract}
This articles reports on the findings of a study carried out in 2003-2004 which examined gender perspectives in the delivery and assessment of junior cycle history. The study was a collaborative effort between the School of Education and Lifelong Learning, University College Dublin, and the Centre for Gender and Women's Studies, Trinity College Dublin. Commissioned by the Gender Equality Unit of the Department of Education and Science, the principal aim of the study was to examine how men and women are represented in the junior cycle history syllabus. The principal focus of this article is to report on a key aspect of the overall research study - namely, the gendered nature of examination questions at junior cycle history and teachers' beliefs in relation to gender equality in the classroom. Central to the study was a survey of the views of practising $(n=249)$ and trainee history teachers $(n=46)$. Key findings included the under-representation of females in the historical narrative and in the state examinations in junior cycle history and the frustration of a significant number of teachers at the lack of gender balance in available teaching materials.
\end{abstract}

\section{Introduction}

This article draws on the findings of a major research project that examined the treatment of gender perspectives in the delivery and assessment of history at junior cycle (i.e. post-primary students aged $12-15$ years). ${ }^{1}$ The report was jointly researched by the School of Education and Lifelong Learning, University College Dublin and the Centre for Gender and Women's Studies, Trinity College Dublin. The Gender Equality Unit of the Department of Education and Science funded the research. Its primary objective was to analyse the way in which both men and women are represented in the junior cycle history syllabus. It was an inclusive study which began from the premise that gender balance in schools means an awareness of and commitment to gender equality which requires that pupils, teachers and the wider education community understand how gender identity is constructed and how gender equality is promoted. It comprised a content analysis of all of the major

*Corresponding author: Centre for Gender and Women's Studies, School of Histories and Humanities, Trinity College Dublin, Dublin 1, Ireland. Email: Jennifer.Redmond@tcd.ie 
textbooks used at junior cycle history level, an analysis of junior cycle history examination papers over a ten-year period (1992-2002), a survey of pre-service history teachers and a survey of post-primary history teachers. The published report provides significant insight into the gendered nature of the history syllabi being taught across Irish post-primary schools, teachers' attitudes towards the importance of gender equality, the centrality of examinations to pedagogy and practice and the need for the provision of continuous professional development for all teachers. This article specifically focuses on the gendered nature of examination questions at junior cycle history and teachers' beliefs in relation to gender equality in the classroom. It highlights the interdependent relationship between the syllabus, textbooks and examinations.

\section{Discourse on gender equality in education}

In line with and influenced by international moves towards the promotion of equality in schools, Irish educational policy over the last ten years has espoused a careful commitment to the promotion of gender equality. The Green Paper Education for a Changing World (Government of Ireland, 1992) underlined the importance of all educational institutions developing and publishing 'an active policy to promote gender equality' as well as the need to review all teaching materials on an ongoing basis (pp. 70-71). The Report of the National Education Convention (Coolahan, 1994) pointed to the need to examine 'the context of knowledge ... in a variety of subject areas' because of its importance in the formation of 'self-image and stereotypes' (p. 119). The White Paper Charting our Education Future (Government of Ireland, 1995) stressed the importance of ensuring that the way in which subjects are taught 'does not unwittingly reinforce gender bias' (p. 130). The Education Act (1998) recommended that schools should aim to 'promote the moral, spiritual, social and personal development of students ... [and] promote equality of opportunity for both male and female students' (p. 13).

However, while there has been an apparent commitment to the promotion of gender equality in schools at policy level, this has not translated into the development of curriculum materials or changes in the design of examinations and teaching practices in schools. In this article it will be seen that an examination of textbooks (the primary vehicle for promoting the curriculum), an analysis of examination questions (the most significant variable to influence practice), and a survey of teachers' attitudes, both at pre-service and in-career, point to the fact that gender equality is often sidelined in favour of 'grinding' students for the demands of state examinations.

\section{Methodology}

The central focus of this article, and a major focus of the research project, was to look at how examinations shape the way in which teachers deliver the history syllabus at 
junior cycle in Irish post-primary schools. The ability of examinations to reproduce existing stereotypes, in particular in relation to gender, has been the subject of much debate in the literature (see, for example, Stobart et al., 1992; Epstein et al., 1998, Elwood \& Carlisle, 2003). The examination system is regarded as the most significant variable that influences pedagogy and practice in Irish schools (Points Commission, 1999). Despite recommendations by the National Council of Curriculum and Assessment (NCCA) that a variety of assessment modes be adopted at junior cycle level, the majority of subjects, including history, continue to be examined by terminal examination (NCCA, 1999).

The history examination at junior cycle has two levels, ordinary and higher. The key distinction between these two levels is that the higher level examination comprises two additional sections that require more detailed and analytical answers on the part of the student. Both the questions and illustrative material on examination papers for the period 1992-2002 were analysed. In order to produce a gendered analysis of examination questions, it was necessary to quantify how men and women were represented in questions and the types of questions asked about them. Content analysis refers to the detailed scrutiny of the types of questions asked in textbooks, and the relationship of the questions to the text (Shapiro \& Markoff, 1997; Fraenkel \& Wallen, 2006). It was felt this was the most appropriate method to use in order to produce a nuanced account of the gendered nature of textbooks. Questions were categorised according to whether or not they were 'Male' (questions which named specific male individuals or specific male groups); 'Female' (questions which named either specific female figures or specific female groups); 'Male and Female' (questions which named either specific men and women together, or specific groups which included male and female membership, or questions which referred to 'people' generally); or 'Other' (gender-neutral questions which did not have a gendered dimension, but were about, for example, specific events or objects, inventions or buildings). For the purposes of this article, our focus is not on the gender-neutral questions. They form almost half of all questions, but as they are about objects and events they do not require that the pupil answer with information on men/male groups or on women/female groups.

Examination questions were further classified according to whether or not they were 'open,' 'closed' or 'non-gendered'. A 'closed' question indicated a question which was framed in such a way as to mean that it was exclusive to one gender or another. An 'open' question indicated a question which was framed in such a way as to mean that it was open to both males and females. Questions were defined as 'nongendered' if they were not specifically about males or females, but may have been about specific historical events or historical artefacts.

Of the 249 respondents to the questionnaire, 99 wrote narrative comments which were typed and coded according to gender and school type. This section was included in order to allow teachers to write openly about their views on the issue of gender balance and on the survey itself. Allowing for the voices of participants in research to emerge is a significant component of qualitative inquiry (Weinberg, 2002). 


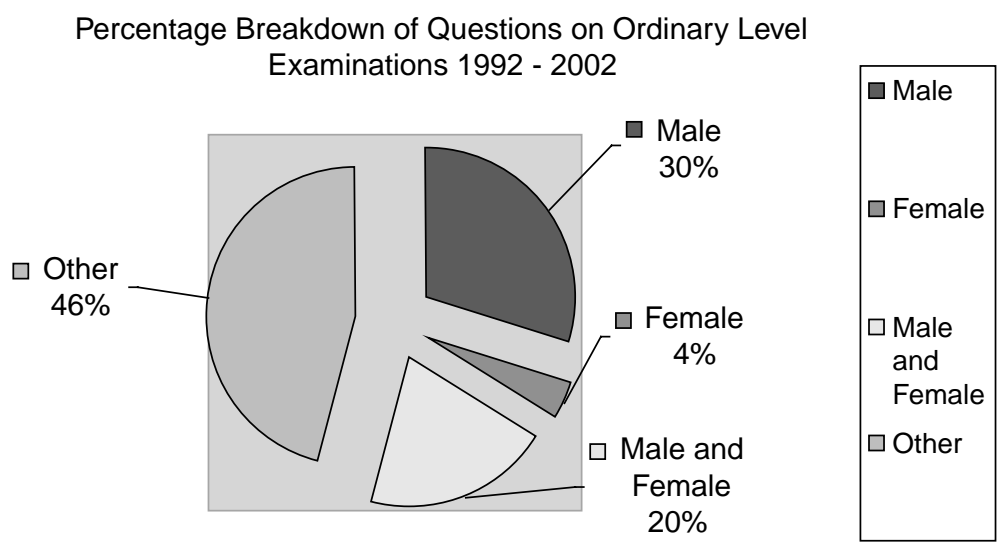

Figure 1. Percentage of ordinary level examination questions by gender, 1992-2002

\section{Findings}

\section{Examination papers 1992-2002}

A total of 536 exam questions were analysed at ordinary level. Figure 1 indicates the total percentage breakdown by gendered categories of the questions asked on the ordinary level examination.

Table 1 shows the numerical breakdown of these questions into gendered categories.

On the ordinary level examinations, the data reveal that questions on males outnumber questions on females by over $7: 1$. Questions on males similarly outnumbered questions on males and females together by over 1.5:1. Moreover, a detailed analysis of the examination on a yearly basis over the time period 1992-2002 exposes the fact that there are four years where there are no questions at all in the 'Female' category. This is not the case for any of the other gender categories. At ordinary level, the total number of closed questions for the period 1992-2002 was 182 , with $87.6 \%$ of those relating to males only, and $12.4 \%$ of them relating to females only.

The same form of analysis was applied to the higher level paper. The total number of questions analysed at higher level was 858 . Figure 2 shows the total percentage breakdown by gendered categories of the questions asked at higher level.

Table 1. Total breakdown of ordinary level examination questions by category

Examination Questions Gender Category

Male

Female

Male and Female

Other
Total Number of Questions 
Breakdown of Higher Level Examination

Questions 1992 - 2002

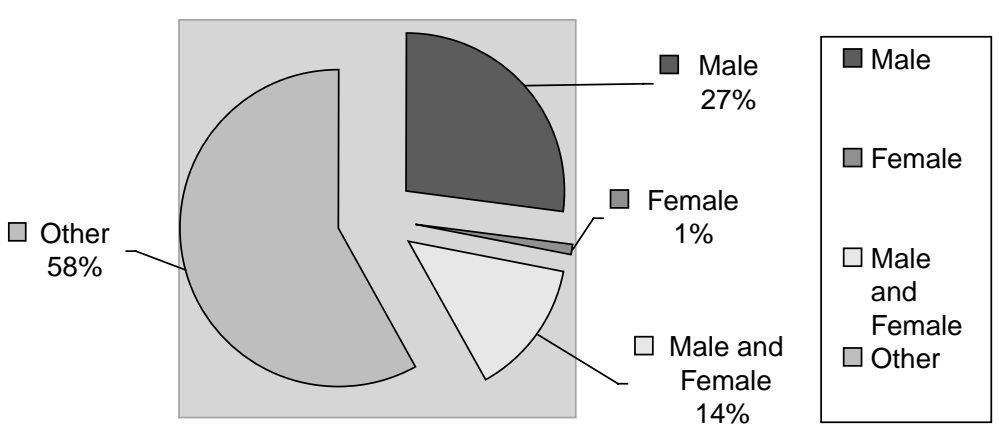

Figure 2. Breakdown of higher level examination questions by gender, 1992-2002

Table 2 shows the numerical breakdown of these questions into gendered categories.

It can be seen from these data that questions on males outnumber questions on females by over $22: 1$, and on males and females by almost $2: 1$. In addition, analysis of the higher level examinations on a yearly basis revealed that there were three years in the time period (1992-2002) where there were no questions at all about women. The total number of closed questions for the period 1992-2002 on the higher level paper was 239 , with $95.56 \%$ of those relating to males only, and $4.44 \%$ of them relating to females only.

Comparing both the ordinary and higher level papers, there is a 3\% cumulative increase in questions about females exclusively on the ordinary level paper and a $6 \%$ increase in questions about males and females together. However, the total number of questions on women, or on men and women together, remains low. These figures are surprising given that there is potentially greater opportunity to answer questions on women in the higher level examination, which reveals that even when material on women could be included it has not been. When gendered questions predominate at either level, they are questions solely about men. These data illustrate that gender balance will not be successfully fostered in schools if teachers are teaching towards the examinations in their current form.

Table 2. Total breakdown of higher level examination questions by category

Examination Questions Gender Category Total Number of Questions

Male

Female

Male and Female

117

Other

502 


\section{D. Raftery et al.}

\section{Illustrative material}

Illustrative material forms a central part of the examination of junior cycle history, both at ordinary and higher level. In the sources section, students are invited to comment on particular images, including artists' impressions, photographs, propaganda and primary source material. In analysing the gendered nature of illustrative material in the examinations, the same methodology was employed as in the questions, with the same gender categories used. In addition, representation codes were applied in order to categorise what was depicted in the illustrations. There were twenty-three representation codes in total, including 'Other' to describe illustrations of buildings and other non-gendered objects. Examples of illustration codes include: 'as political leaders', 'as subjects of art', and 'as wife or partner of'.

A total of 101 images were analysed on higher level examination papers for the period 1992-2002. The figure for ordinary level for the same period was 105 . In keeping with the results of the analysis of textbooks, images of women on their own in examination papers were rare, with the majority of images relating to the role of male figures in political or military history.

In comparing the ordinary and higher level examinations, it is important to note the differences between the two examinations and thus the differences in the questions asked and the depth of the answers required. At present, the extra sections of the higher level examination contain more in-depth questions on social change, which often require an exploration of the changes in the status of women in society over the last century. This effectively means that at higher level, students are afforded greater opportunity to research and answer questions on issues relating to women.

At both ordinary and higher level, the use of gender-neutral or gender-inclusive language emerged as a significant issue. In line with a climate of inclusivity, recent examination papers, like recent textbooks, employ a gender-neutral language. Students are therefore asked to respond to a question referring either to the historical experience of men or women using 'he/she' or 'his/her' phraseology. While this development is certainly welcome, students are limited in their ability to answer on the historical experience of women because of the dearth of information in all of the mainstream textbooks on women. Hence, the ostensible commitment to the promotion of gender equality in schools has not been matched by a genuine commitment in the development of curriculum materials, the design of examinations, and teaching practices in schools. As demonstrated in the data analysis, the information in textbooks available to teachers displays a distinct gender imbalance in the material related to men and women. Similarly, in the analysis of examination papers, it was found that much material related solely to men or male historical characters, and the constraints of available information in the textbooks would limit a candidate's answers to references to men. Given the evidence on available material, it is thus interesting to turn to the views of practising teachers in order to gauge their assessment of and reaction to the gender imbalance in their teaching materials. 


\section{Views of pre-service teachers}

A significant part of the research effort was to ascertain the views of pre-service teachers in relation to the delivery and assessment of junior cycle history. One of the principal objectives of the research was to ascertain how teachers perceive examinations, how examinations shape practice and how teachers prepare pupils for examinations. A convenience sample of pre-service teachers participating in the Higher Diploma in Education at University College Dublin in the academic year 2003-4 was surveyed. ${ }^{2}$ Respondents had been educated at schools throughout the country and were undertaking teaching practice in schools in the greater Dublin area. There were forty-six respondents in total. ${ }^{3}$ The majority were teaching at single-sex female secondary schools (41\%), while $35 \%$ were teaching at single-sex male secondary schools and $24 \%$ were teaching in mixed schools. Of these schools, $15 \%$ were accorded designated disadvantage status. The majority (66\%) had taken junior cycle history while at school. They had been taught by both male and female teachers: $43 \%$ were taught by male history teachers only; $26 \%$ were taught by female history teachers only, and $31 \%$ were taught by both.

Pre-service teachers indicated that examinations were central to the development of their practice and teaching style. They also indicated the pressure placed upon them by the responsibility of preparing pupils for state examinations, even while still becoming qualified. This pressure was also identified by new and beginning teachers in their first year, post-qualification, many of whom are given sole responsibility for exam classes, particularly at junior cycle level (Killeavy et al., 2006).

As a result of the prominence of state examinations in post-primary education in Ireland, pre-service teachers indicated that they relied principally on textbooks as the most reliable means of delivering the syllabus. Fifty-four per cent of those surveyed noted a tendency to rely exclusively on the textbook in their own teaching. Despite heavy reliance on the textbook, respondents indicated both a general dissatisfaction with the textbook and a realisation that the textbook presented a narrow view of women's role in history. Ninety-three per cent of those surveyed felt that there was a need to revise existing textbooks in order to include greater focus on the experience and contribution of women in history. If textbooks were altered/improved in this manner, it would enhance the ability of the student to answer questions equally on men or women. It would also aid teachers to teach a more gender-balanced curriculum. These findings echo those of a study on the integration of gender in school geography, which found a need for a substantial body of relevant resources for teachers in order to allow them to address the issue of gender in the delivery of geography (Lane, 1990).

While best practice in the promotion of gender equality in teaching would advocate the importance for teachers of assessing the quality of their teaching materials to identify whether or not 'equal numbers of women and men are portrayed' (Cohen et al., 1996, p. 253), opportunities for such reflection are not always available in the busy climate of Irish schools. 


\section{D. Raftery et al.}

\section{Views of practising teachers}

A central aspect of the research was to gather the views of practising teachers on the delivery and assessment of junior cycle history and the promotion of a genderbalanced curriculum. A questionnaire was piloted in September 2003 at the History Teachers' Association of Ireland annual conference. Any necessary adjustments were then made and the final instrument was subsequently posted out to all post-primary schools in the country. When the questionnaires were returned, the quantitative data were coded and analysed using the Statistical Package for the Social Sciences (SPSS) and a content analysis was carried out on the qualitative part of the instrument. Of the 751 schools surveyed, 249 questionnaires were returned, which was almost one third. The breakdown of the sample was as follows: 147 secondary schools $(60 \%)$, of which 29 were fee-paying and 118 were non-fee-paying; 64 vocational schools $(26 \%) ; 21$ community schools $(8 \%)$ and 6 comprehensive schools (2\%). Eleven schools $(4 \%)$ did not indicate a school type. The profile of those returning the questionnaire was as follows: females: $57 \%$; males: $40 \%$; non-responsive: $3 \%$. Fortyfive per cent of respondents had been taught by male history teachers, $41 \%$ by female history teachers, and $14 \%$ were taught by both.

As with the questionnaire administered to pre-service teachers, a principal objective of the research was to ascertain the views of practising history teachers on the role and centrality of the state examinations and the ways in which they tailored their teaching to suit the requirements of the examination process. In keeping with the views expressed by pre-service teachers, practising history teachers indicated that examinations were central to their practice and attitude towards the teaching of history. Ninety-six per cent of those surveyed believed that men's contributions and experiences were given full or moderate attention in the junior cycle history examination. However, only $4 \%$ of female respondents and $11 \%$ of male respondents believed that women were given adequate attention in the history junior cycle examination. Female respondents in particular registered their belief that the junior cycle history examination should be revised to include questions on women's experience of and contribution to history. The view was expressed that if questions on women's history were not included in the examination, teachers would be unlikely to include women's history in their teaching. As one respondent noted, 'the sad fact is that most teachers will concentrate on what they think will come up in the exam'.

The majority of respondents indicated a tendency to rely heavily on the textbook in preparing pupils for examinations. Yet, in keeping with the views of pre-service teachers, there was an overwhelming sense of dissatisfaction registered by practising teachers with the current range of textbooks in use in Irish schools. A total of $74 \%$ of female respondents and $52 \%$ of male respondents noted that there was a pressing need to revise existing textbooks. Comments by some female respondents in the open-ended section of the questionnaire included 'female perspectives are all but ignored in most textbooks' and 'the gender imbalance of our textbooks could use some attention'. 
This research suggested that a substantial cohort of teachers was not aware of or concerned about whether or not they were promoting gender equality in the classroom. We would support the views of other scholars in the field who recommend that training in systematic self-analysis and critical reflection on teaching and on the promotion of gender equality in the classroom must form a central part of teacher education programmes both at pre- and in-service levels (Drudy \& Uí Chatháin, 2002). The benefit of reflective practice to teacher development and to the profession generally is widely acknowledged (Brookfield, 1995; Zeichner \& Liston, 1996). The promotion of reflective practice includes critical appraisal of teaching methodologies, teaching and learning resources, evaluation and assessment procedures and the use of textbooks, all of which are fundamental to the promotion of gender equality, within both the formal and the hidden curriculum.

\section{Conclusion}

Whilst there have been developments in the discourse on gender equality in education and other settings over the last decade, such discourse has not impacted sufficiently on the way in which gender equality is promoted in Irish schools. This is particularly evident in subjects such as history, where the experience and contribution of women continues to be marginalised. To quote from one respondent to the questionnaire: 'women have been effectively sidelined in History. The cast of male characters in history lessons suggest women's roles were as victims or mere handmaidens to the starring males. This is hardly likely to attract girls to the study of history'. As Ward (1991) notes, 'in the case of history textbooks, it is only when the extent of women's relegation to the footnotes is clearly seen, that the urgency of the task of pointing this out becomes apparent' (pp. 4-5).

Our research highlights a number of important issues in relation to examinations and the promotion of gender equality. First, in the short term, the junior cycle history examination must be revised to include more questions which can apply equally to either men or women. Second, in the medium to long term, the junior cycle history examination must be reconstructed to include specific questions on women's history and documents and illustrative material on women. However, in order for pupils to be prepared to answer questions on women's history, the junior cycle history syllabus must also be revisited to include more sections and material on women. These revisions must promote women as real and meaningful agents in the historical narrative and not just as subordinates to male historical actors. Because of the interdependent relationship between the syllabus, textbook and examination, the textbooks must also be revisited to include more accurate and comprehensive information of women. Additional resource material must also be made more accessible for teachers and pupils who wish to explore particular aspects of women's history.

The prominence of the terminal assessment at junior and leaving certificate level in Irish schools creates certain pressures for teachers, as well as pupils. Not least is the pressure to prepare thoroughly for the written examinations. Gender equality in the 
classroom will continue to be marginalized unless it becomes a reality of this examination process. However, reforming the examination system is not sufficient, as attitudes towards the importance of gender equality will also have to be addressed. Like other researchers in the field, we would caution that gender equality cannot be realised simply by the manipulation of assessment techniques (Stobart et al., 1992).

If gender equality is to be genuinely promoted in Irish education, three variables must be revisited: the syllabus, the textbook and the examination. The syllabus, the cornerstone of teaching in Irish schools, should reflect equity and balance. While it is recognised that a balance in content may still not ensure parity of esteem accorded to men and women in classroom practice, the provision of balanced materials would go a long way towards creating a teaching and learning context which values gender equality. Textbooks, the most powerful vehicles for delivering the syllabus, should respond to syllabus change, and should provide sufficient material that pupils may learn about the lives and work of both men and women in the past. While the provision and utilisation of online resources may go some way towards rectifying or diminishing the gaps in textbooks, it must be recognised that many schools currently lack adequate computer and IT facilities. Such remedies would therefore be unbalanced in terms of their access across the country, and significant resources would need to be made available for such an action. It is also important to note that the textbook is so firmly rooted in educational practice as the soundest method of conveying the curriculum that additional, more gender-balanced information should be included within the textbook. Finally, the state examination, the most significant influence on practice, should be constructed in such a way to allow boys and girls the opportunity to write about both men and women in the historical narrative. Only when examinations are modified will any significant change in the delivery of a gender-balanced curriculum take place: failure to match assessment practice with pedagogical aims is the most significant factor in the failure to change practice (Hanafin \& Leonard, 1995).

\section{Notes}

1. The junior cycle refers to the first three years of post-primary education in Ireland, which culminates in a state examination in each of the subjects undertaken by the pupils.

2. The questionnaire administered had been piloted on the previous Higher Diploma in Education cohort (2002-3) and any necessary adjustments were made. This programme is now titled Post-Graduate Diploma in Education (PGDE).

3. Of the student teachers, 20 were male and 26 were female. Of the practising teachers who were surveyed in the national questionnaire, 143 were female $(57 \%), 99$ were male $(40 \%)$ and 7 did not specify their gender (3\%).

\section{References}

Brookfield, S. (1995) On becoming a critically reflective teacher (San Francisco, Jossey-Bass).

Cohen, L., Manion, L., \& Morrison, K. (1996) A guide to teaching practice (4th ed.) (London, Routledge). 
Commission on the Points System (1999) Report of the Commission on the Points System (Dublin, Stationary Office).

Coolahan, J. (1993) Professionalism in context, in: D. Swan \& M. Leydon (Eds) Teachers as professionals: proceedings of a seminar of the standing committee of teacher unions and university departments (Dublin, Standing Committee of Teacher Unions and University Departments of Education).

Coolahan, J. (1994) Report of the national education convention (Dublin, National Convention Secretariat).

Drudy, S. \& Uí Chatháin, M. (2002) Gender effects in classroom interaction: data collection, selfanalysis and reflection, Evaluation and Research in Education, 16(1), 34-50.

Education Act (1998) Part II, System 9 (e).

Elwood, J. \& Carlisle, K. (2003) Examining gender: gender and achievement in the junior and leaving certificate examinations, 2000/2001 (Dublin, National Council for Curriculum and Assessment [NCCA]).

Epstein, D., Elwood, J., Hey, V. \& Maw, J. (1998) Schoolboy frictions: feminism and 'failing' boys, in: D. Epstein, J. Elwood, V. Hey \& J. Maw (Eds) Failing boys? (Buckingham, Open University Press).

Fraenkel, J. R. \& Wallen, N. E. (2006) How to design and evaluate research in education (6th ed.) (New York, McGraw-Hill).

Government of Ireland (1992) Education for a Changing World: Green Paper on Education.

Government of Ireland (1995) Charting our Education Future: White Paper on Education.

Hanafin, J. \& Leonard, D. (1995) Conceptualising and implementing quality: assessment and the junior certificate, Irish Educational Studies, (15), 26-39.

Hyland, A. \& Hanafin, J. (1996) Models of incareer development in the Republic of Ireland: an analysis, Irish Educational Studies, 16, 144-171.

Killeavy, M. \& Murphy, R. (2006) National pilot project on teacher induction: a final report (Dublin, Irish Government Publications).

Lane, C. (1990) The integration of gender in school geography, in: J. Coolahan (Ed.) Teacher education in the nineties: towards a new coherence: proceedings of the $15^{\text {th }}$ annual conference of the association for teacher education in Europe (Limerick, Mary Immaculate College).

Lortie, D. (1975) The school teacher: a sociological study (Chicago, University of Chicago Press).

National Council for Curriculum and Assessment (NCCA) (1999) Guide to the junior certificate (Dublin, NCCA).

Shapiro, G. \& Markoff, J. (1997) A matter of definition, in: C. W. Roberts (Ed.) Text analysis for the social sciences: methods for drawing statistical inferences from texts and transcripts (Mahwah, NJ, Lawrence Erlbaum Associates).

Stobart, G., Elwood, J. \& Quinlan, M. (1992) Gender bias in examinations: how equal are the opportunities?, British Educational Research Fournal, 28(3), 261-276.

Ward, M. (1991) The missing sex: putting women into Irish history (Dublin, Attic Press).

Weinberg, D. (2002) Qualitative research methods (Malden, MA, Blackwell Publishers).

Zeichner, K. \& Liston, D. (1996) Reflective teaching: an introduction (Mahwah, NJ, Lawrence Erlbaum Associates). 